\title{
REPAIR OF ARTICULAR SURFACES BY ALLOGRAFTS OF ARTICULAR AND GROWTH-PLATE CARTILAGE
}

\author{
JAYNE E. ASTON, GEORGE BENTLEY
}

\author{
From Royal Liverpool Hospital, Liverpool, and The Institute of Orthopaedics, London
}

\begin{abstract}
Allografts of intact cartilage, isolated chondrocytes and cultured chondrocytes taken from the epiphysial growth-plate and from the articular surface of immature rabbits were inserted into full thickness defects in the tibial articular surface of $\mathbf{1 6 0}$ mature rabbits. In the contralateral knees, which were used as controls, similar defects were made but no grafts were inserted. Grafts were followed up for periods of up to one year after transplantation. Both intact articular and intact growth-plate grafts produced significantly better repair than that seen in control ungrafted defects in normal joints $(P<0.01$ and $P<0.05$ respectively) and in arthritic joints $(P<0.01)$. Cultured chondrocytes cut to a precise fit also produced significantly better repair than ungrafted defects in arthritic joints $(P<0.05)$.
\end{abstract}

It is well established that mature articular cartilage has virtually no intrinsic repair capacity, although should the damage extend into the underlying bone marrow spaces, there is repair with fibrous tissue which may or may not undergo metaplasia to form fibrocartilage (Mankin 1982). Analysis of this repair tissue shows it to contain varying amounts of Type I and Type II collagen (Eyre and Muir 1975; Cheung et al. 1978; Furukawa et al. 1980) although it is possible that this may be a reflection of the size of the defect (Convery, Akeson and Keown 1972). In contrast, normal hyaline articular cartilage is thought to contain solely Type II collagen (Miller 1976). Whether the repair cartilage is mechanically inferior to hyaline articular cartilage is still unclear, although there is evidence that it responds differently to compression (Coletti, Akeson and Woo 1972), and that it eventually reverts to a dense fibrous tissue (Mitchell and Shepard 1976).

In view of these findings it seems desirable to look for a means of repairing surfaces which have been damaged by, for instance, osteochondritis dissecans, osteochondral fractures, chondromalacia and early osteoarthritis. Shell osteochondral allografts have been successful in replacing large areas of entire articular surface (Gross et al. 1976; Langer et al. 1978), although the bony component of fresh intact cartilage allografts does present some immunological problems (Elves 1978). An alternative is to consider using cartilage alone as a graft material. The difficulty of fixation of cartilage as a graft

J. E. Aston, PhD, Senior Research Assistant

Department of Orthopaedic and Accident Surgery, University of Liverpool, Royal Liverpool Hospital, Prescot Street, Liverpool L78XP, England.

G. Bentley, ChM, FRCS, Professor of Orthopaedic Surgery

Institute of Orthopaedics, Royal National Orthopaedic Hospital, Brockley Hill, Stanmore, Middlesex HA7 4LP, England.

Requests for reprints should be sent to Professor G. Bentley.

(C) 1986 British Editorial Society of Bone and Joint Surgery $0301-620 X / 86 / 1008 \$ 2.00$ precludes its use for total surface replacement, but in the present investigation we have concentrated on replacing a limited area, so overcoming this problem. Articular cartilage has the advantage of appearing to be an immunologically privileged tissue and has been shown to have the ability to repair experimental defects both as intact tissue (McKibbin 1971) and as isolated chondrocytes (Bentley and Greer 1971); in both instances the graft material was from immature animals. Where isolated chondrocytes from mature donors were used, no repair was evident (Chesterman and Smith 1968). In addition, there is evidence that chondrocytes isolated from the epiphyses of immature rabbits have a greater repair capacity than cells isolated from the immature articular surface (Bentley, Smith and Mukerjhee 1978).

In view of these previous findings a study was made of the ability of such immature grafts to repair defects in joint surfaces over periods up to one year. In addition, since any possible clinical application would require storage of the grafts, in vitro culture was investigated as a possible method and the subsequent success of such cultured chondrocytes in repairing defects was assessed. A previous short-term study has shown that cultured chondrocytes do have some ability to repair defects (Green 1977). In the first series of experiments grafts were inserted into normal joints, while in the second series the joints had a degenerative type of arthritis induced by intra-articular injections of the enzyme papain.

\section{MATERIALS AND METHODS}

Donor articular and growth cartilage was taken respectively from the articular surfaces and growth plates of the knee joints of immature New Zealand White rabbits, aged five to six weeks. Care was taken during dissection to eliminate any contaminating tissue. The articular cartilage was sliced to full depth, after which the perichondrium was stripped from around the bone in the region of the growth plate. The diaphysis was snapped off and the growth-plate cartilage sliced off the bone so as to include all zones, but with the exclusion of any bone. Samples were taken of both articular and growth cartilage; the presence 
of cell zones of the growth plate, and the absence of bone were confirmed by histology. This donor cartilage was prepared in one of three ways prior to grafting.

Isolated chondrocytes. The cartilage was diced and washed with Dulbecco's phosphate-buffered saline (PBS-Gibco Europe). The matrix was digested to release the cells, using a combination of trypsin (Difco) $0.25 \% \mathrm{w} / \mathrm{v}(2.5 \mathrm{~g} / \mathrm{l})$ in PBS and collagenase (Type 1-Sigma) $0.05 \% \mathrm{w} / \mathrm{v}(0.5 \mathrm{~g} / 1)$ in Ham's F10 medium (Gibco Europe) buffered with $20 \mathrm{mmol} / 1$ hydroxyethylpiperazine ethane sulphonic acid (Hepes - Flow Laboratories). Both solutions were filter-sterilised prior to use.

Articular cartilage was digested using a modification of the protocol of Bentley and Greer (1971), with incubation in $0.25 \%$ trypsin for 30 minutes followed by incubation with $0.05 \%$ collagenase for a total of 16 to 19 hours.

Growth cartilage was digested by incubation with trypsin for 30 minutes, followed by two incubations with collagenase each of 21 to 3 hours duration (Aston 1980). Both dissociation procedures were carried out at $37 \mathrm{C}$ in a shaking water incubator. After isolation the cells were washed twice with Ham's F 10 medium followed by centrifugation in a Sorvall GLC 3 bench centrifuge at $800 \mathrm{rpm}$ for 5 minutes. The chondrocytes were then resuspended in a small amount of medium and a cell count carried out. The viability was assessed routinely using the trypan blue dye exclusion test.

Cultured chondrocytes. The method of culture was modified from the procedure used by Fitton-Jackson (1975). The chondrocytes were seeded at densities of $0.7 \times 10^{3} \mathrm{cells} / \mathrm{mm}^{2}$ and $1.5 \times 10^{3} \mathrm{cells} / \mathrm{mm}^{2}$ for articular and growth-plate chondrocytes respectively into $30 \mathrm{~mm}$ diameter tissue-culture dishes (Sterilin Ltd) containing $2 \mathrm{ml}$ of Ham's F10 medium buffered with $20 \mathrm{mmol} / 1$ Hepes and containing $10 \%$ fetal calf serum (FCS-Gibco Europe), $100 \mathrm{iu} / \mathrm{ml}$ and $100 \mu \mathrm{g} / \mathrm{ml}$ of penicillin and streptomycin respectively (Squibb Ltd) and $50 \mu \mathrm{g} / \mathrm{ml}$ of ascorbic acid.

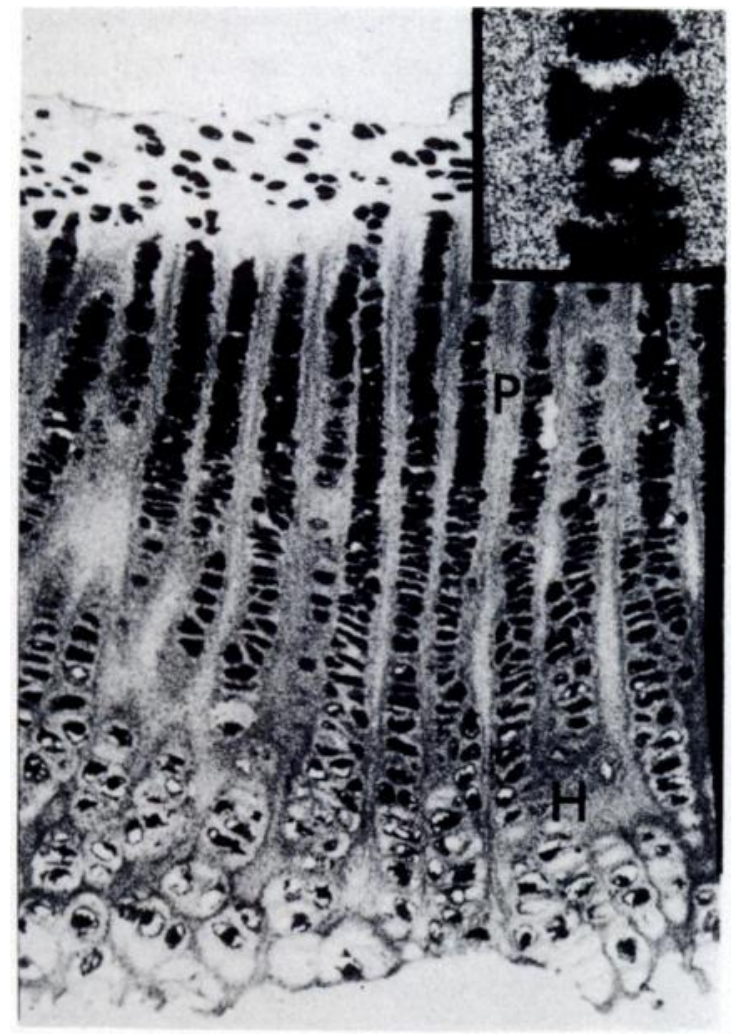

Fig. 1

Donor intact growth-plate cartilage plug showing uptake of $\left[{ }^{3} \mathrm{H}\right]$ leucine which demonstrates active protein synthesis in the proliferative $(P)$ and hypertrophic $(H)$ zones $(\mathrm{H} \& \mathrm{E}$, $\times(50)$. Inset: high-power view showing intense labelling of the cells in the proliferative zone.
After three to four days, when the chondrocytes had attached, the medium was changed twice weekly. By four weeks in culture a sheet of tissue had formed which was pushed together and transferred to an organ-culture grid for a further two weeks in culture. After a total of six weeks, the cultures were ready to be allografted. (Initially five-week cultures were used, but achieved little success.) Six-week cultures of both ar icular and growth-plate chondrocytes were incubated with complete Ham's F 10 medium containing either $20 \mu \mathrm{Ci} / \mathrm{ml}$ of $\left[{ }^{3} \mathrm{H}\right]$ thymidine (to indicate cell division) or $50 \mu \mathrm{Ci} / \mathrm{ml}$ of sodium $\left[{ }^{35} \mathrm{~S}\right]$ sulphate (to indicate matrix production of proteoglycan) for 24 hours at 37 . The cultures were washed, fixed in neutral buffered formol saline and embedded in wax. Sections were cut $6 \mu \mathrm{m}$ thick for autoradiography and histology.

Autoradiographs were prepared by overlaying the sections with AR 10 stripping emulsion (Kodak) with exposure for two weeks at $4 \mathrm{C}$, following which they were developed with Kodak D19 and fixed with Kodafix. Histological sections were stained with either haematoxylin and eosin (H \& E) or toluidine blue. Samples were also fixed in $3 \%$ glutaraldehyde and $2 \%$ aqueous osmium, stained with $2 \%$ uranyl acetate and Reynolds' lead citrate, and viewed in an AE1 EM6B transmission electron microscope.

Intact cartilage. Plugs of cartilage measuring $2 \mathrm{~mm}$ diameter were cut from the articular surface of the distal femur and the growth plate of the proximal tibia since these sources produced the most uniform grafts. These plugs of cartilage were maintained on organ-culture grids in Ham's F10 medium plus 10\% FCS for not more than 24 hours before grafting. Routine histology was carried out and in addition some samples were incubated with radio-isotopes which included $\left[{ }^{3} \mathrm{H}\right]$ thymidine, sodium $\left[{ }^{35} \mathrm{~S}\right]$ sulphate and $\left[{ }^{3} \mathrm{H}\right]$ leucine (to indicate protein synthesis). Incubations were carried out over a period of 24 hours at $37 \mathrm{C}$ in Ham's F10 medium with $10 \%$ FCS, containing either $20 \mu \mathrm{Ci} / \mathrm{ml}$ or $50 \mu \mathrm{Ci} / \mathrm{ml}$ of isotope. The cartilage plugs were prepared for histology and autoradiography as described for the cultured chondrocytes.

\section{GRAFTING PROCEDURE}

The recipients were two groups of mature New Zealand White rabbits. In one group the joint was normal. In the second group a degenerative type of arthritis had been induced by three intra-articular injections of the enzyme papain (BDH Chemicals) over a one-week period, as previously described for the hip (Bentley 1971). Grafting was carried out six weeks later. In both groups the opposite knee was used as a control.

A lateral incision was made into the knee joint so as

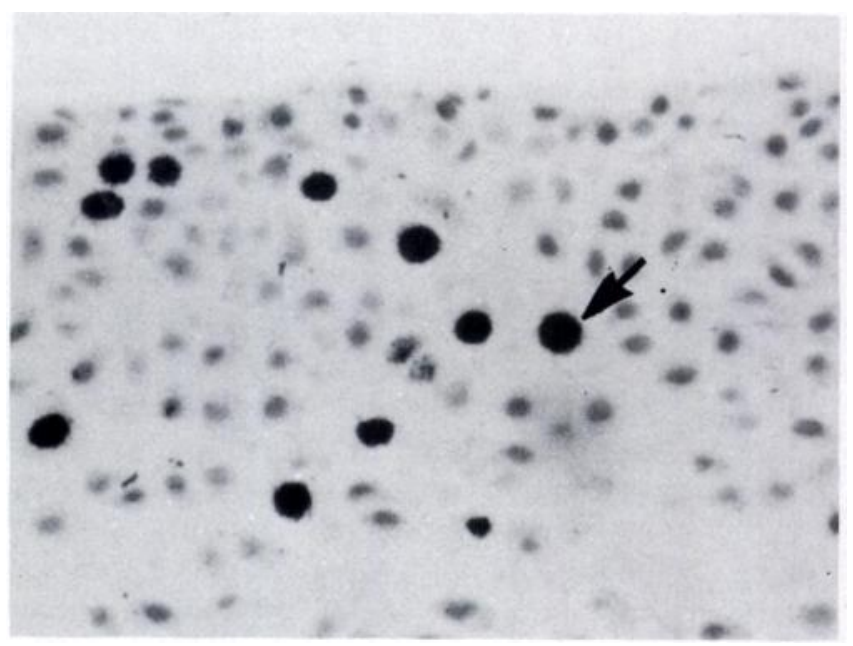

Fig. 2

Donor intact articular cartilage plug showing uptake of $\left[{ }^{3} \mathrm{H}\right]$ thymidine by many chondrocytes at the surface, indicating cell division (arrow) $(H \& E, \times 600)$. 


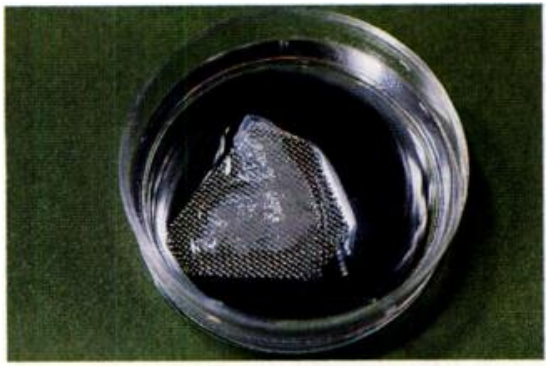

4 Fig. 3

Culture of articular chondrocytes after being transferred to an organ-culture grid for the final two weeks in culture.

Fig. $4 \square$

Six-week culture of articular chondrocytes showing the cells in lacunae surrounded by metachromatically staining matrix (toluidine blue, $\times 900$ ).

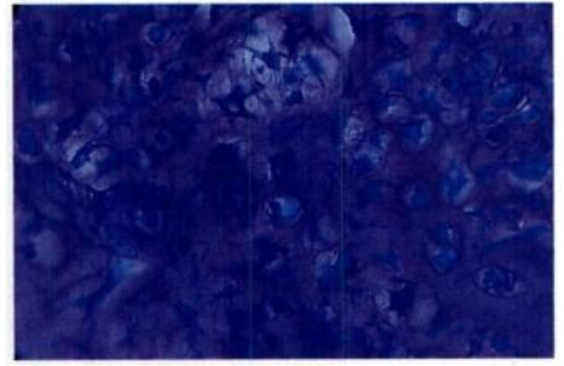

to expose the lateral tibial articular surface and, using a hand drill, a defect $2 \mathrm{~mm}$ in diameter was made in the centre of the weight-bearing region. The defect was washed with saline and dried with a swab to remove any bone debris. When isolated chondrocytes were used for the graft, these were put into the defect using either a pipette or a large-gauge needle. When intact cartilage was grafted, the cartilage plugs were push-fitted into place. The cultured chondrocytes were used in one of two ways: in the group with normal joints, a portion of the cultured chondrocytes was cut and pushed into the defect, but some of these grafts were lost; therefore, in the group with induced arthritis, the later chondrocyte cultures were cut to precise size in the same way as the intact pieces (earlier five-week cultures were not cut to size). The control defect made in the opposite knee joint was left empty after it had been washed and swab-dried. The joints were closed with 2-0 catgut and the skin with 2-0 black silk. Postoperatively the joints were checked for infection and the rabbits were allowed unrestricted activity in their cages.

The grafts were followed for periods of 2 weeks, 6 weeks, 3 months, 6 months and 1 year, after which the knees were checked for any restriction of movement and the rabbits were killed with an overdose of Sagatal administered intravenously. The tibial heads were removed and the presence of any synovial pannus noted. The specimens were incubated in Ham's F10 medium plus $10 \% \mathrm{FCS}$ containing $50 \mu \mathrm{Ci} / \mathrm{ml}$ of either $\left[{ }^{3} \mathrm{H}\right]$ thymidine or sodium $\left[{ }^{35} \mathrm{~S}\right]$ sulphate for 24 hours at $37^{\circ} \mathrm{C}$. Following this incubation the heads were washed with medium, fixed, decalcified and wax embedded; $6 \mu \mathrm{m}$ sec-

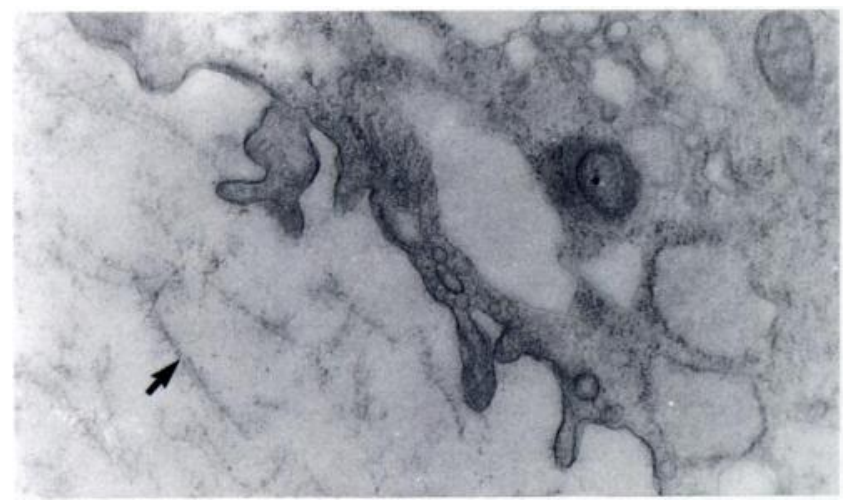

Fig. 5

Electron micrograph of an articular chondrocyte after culture for six weeks showing fine collagen in the matrix (arrow) $(\times 15000)$. tions were cut for histology and autoradiography and prepared as described earlier.

\section{RESULTS}

Assessment of donor material. The viability of the freshly isolated chondrocytes was consistently $95 \%$ as judged by the trypan blue dye exclusion test, although a sample examined on an ultrastructural basis by transmission electron microscopy showed a viability of $80 \%$. Histology of the intact cartilage grafts confirmed the absence of bone in both articular and growth-plate material, but in some cases the proliferative zone of the growth plate was incomplete. Uptake of sodium $\left[{ }^{35} \mathrm{~S}\right]$ sulphate and $\left[{ }^{3} \mathrm{H}\right]$ leucine was evident in the majority of cells (Fig. 1), and a few cells in the superficial zone of the articular cartilage plugs demonstrated uptake of $\left[{ }^{3} \mathrm{H}\right]$ thymidine (Fig. 2).

After six weeks in culture the chondrocytes had formed a type of reconstituted cartilage (Fig. 3); histologically, chondrocytes were seen to be surrounded by a metachromatically staining matrix with the cells inside lacunae (Fig. 4). These cells demonstrated uptake of sodium $\left[{ }^{35}\right.$ S $]$ sulphate predominantly in the pericellular region compared with frozen controls where there was no uptake. Cultured articular chondrocytes also demonstrated uptake of $\left[{ }^{3} \mathrm{H}\right]$ thymidine with approximately $11 \%$ of cells showing the label. In comparison, cultured growth-plate cells showed only the occasional labelled celis. Ultrastructurally, the cells were seen to be surrounded by a matrix which contained fine unbanded collagen fibres (Fig. 5). Ultrastructural assessment of viability on four samples of cultured articular chondrocytes and one sample of cultured growth-plate chondrocytes gave values of $70 \%$ and $59 \%$ respectively. A sample of articular chondrocytes labelled for collagen Types I, II and III by the indirect fluorescent antibody test demonstrated the greatest fluorescence with Type II antibody with only faint fluorescence for Types I and III.

Assessment of grafted and control defects. It was not always possible to tell from photographs of the macroscopic appearance whether the grafts had been successful. However, in a few cases successful repair was obvious (Fig. 6).

The grafts were assessed histologically for success in filling the defects: successful-where there was complete or near-complete filling of the defect with graft tissue (Fig. 7); unsuccessful-where there was only minimal 
Table I. Success rate of repair of defects in normal joints

\begin{tabular}{|c|c|c|c|c|c|c|c|c|c|}
\hline \multirow[b]{2}{*}{ Type of graft } & \multicolumn{5}{|c|}{ Age of graft at postmortem analysis } & \multicolumn{2}{|c|}{ Total successful } & \multicolumn{2}{|c|}{ Complete filling } \\
\hline & 2 weeks & 6 weeks & 3 months & 6 months & 1 year & No. & $\%$ & No. & $\%$ \\
\hline Isolated articular chondrocytes & $0 / 3$ & $1 / 4$ & $3 / 4$ & $2 / 3$ & $1 / 4$ & $7 / 18$ & 39 & $6 / 18$ & 33 \\
\hline Isolated growth-plate chondrocytes & $2 / 4$ & $1 / 4$ & $2 / 4$ & $2 / 4$ & $1 / 3$ & $8 / 19$ & 42 & $6 / 19$ & 32 \\
\hline Cultured articular chondrocytes & $1 / 2$ & $1 / 4$ & $2 / 2$ & $0 / 3$ & $2 / 3$ & $6 / 14$ & 43 & $4 / 14$ & 29 \\
\hline Cultured growth-plate chondrocytes & $0 / 2$ & $2 / 4$ & $2 / 4$ & $2 / 4$ & $1 / 4$ & $7 / 18$ & 39 & $4 / 18$ & 22 \\
\hline Intact articular cartilage & $4 / 4$ & $4 / 4$ & $3 / 4$ & $3 / 4$ & $2 / 4$ & $\begin{array}{l}16 / 20 \\
P<0.01\end{array}$ & 80 & $16 / 20$ & 80 \\
\hline Intact growth-plate cartilage & $2 / 2$ & $3 / 4$ & $2 / 4$ & $0 / 4$ & $2 / 4$ & $\begin{array}{c}9 / 18 \\
P<0.05\end{array}$ & 50 & $6 / 18$ & 33 \\
\hline Controls & $1 / 13$ & $9 / 23$ & $8 / 22$ & $5 / 19$ & $4 / 17$ & $27 / 94$ & 29 & $11 / 94$ & 12 \\
\hline
\end{tabular}

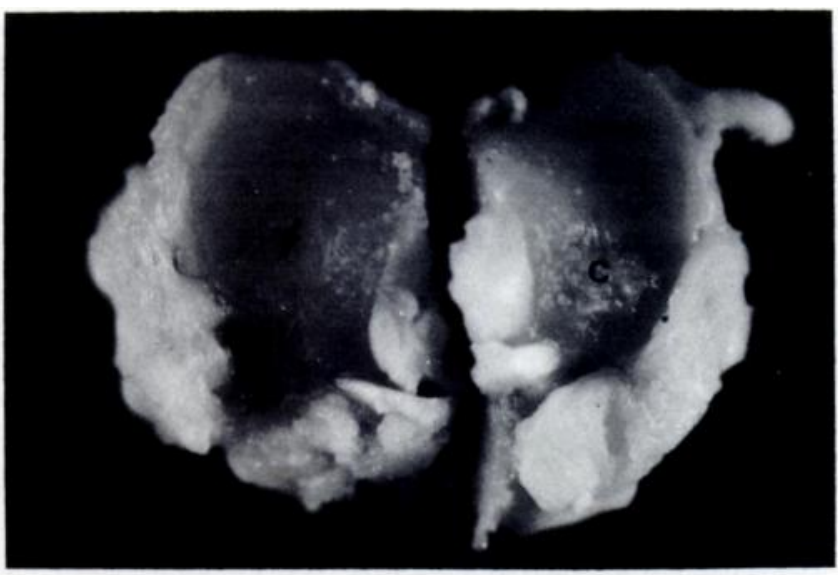

Fig. 6

Macroscopic appearance of a successful allograft after one year (arrow): it has the same appearance as the surrounding cartilage. The control defect $(C)$ is overfilled with fibrillar tissue.

cartilage present plus fibrous tissue, or fibrous tissue alone present in the defect (Fig. 8*). Account was also taken of the level of the surface, i.e. raised or sunken, and also of its integrity.

Controls were similarly assessed bearing in mind that any fibrocartilage in the defect had arisen from subchondral marrow and was, therefore, metaplastic.

\section{Results of grafting in normal joints}

The results of grafts into normal joints are shown in Table I. A total of 112 rabbits received allografts but deaths during the experimental period caused a reduction in the numbers quoted. There did not appear to be a problem with rejection of the grafts, although this was based solely on histological observation of numbers of lymphocytes in grafted versus control defects. All types of grafts produced repair more frequently than that seen in the ungrafted control defects (29\% successful), although only with the intact articular cartilage $(80 \%$ successful) and intact growth-plate cartilage $(50 \%$ successful) was this significant $(P<0.01$ and $P<0.05$

\footnotetext{
* Colour pictures (Figs 7 to 18) will be found on page 35.
}

respectively). In all the successful grafts, apart from the intact articular cartilage group, there was a tendency for the graft surface to become fibrous over prolonged periods (Fig. 9) and there was an apparent decrease in sulphate uptake when compared with the recipient tissue.

In the case of intact articular cartilage grafts, metaplastic tissue from the host was seen to merge with the graft in the early periods of follow-up (Fig. 10); in later grafts the base had been replaced by bone, and articular cartilage of the graft appeared identical to that of the recipient (Fig. 11). This grafted cartilage did not always show complete union at the surface with the recipient cartilage, but the uptake of sodium $\left[{ }^{35}\right.$ S $]$ sulphate appeared comparable (Fig. 12).

The intact growth-plate grafts showed a change in appearance with time. Initially the appearance was that typical of a growth plate (Fig. 13), while after a prolonged period its appearance altered and took on a form similar to the recipient articular surface (Fig. 14), although the surface did have reduced metachromatic staining and there was decreased uptake of sodium $\left[{ }^{35}\right.$ S]sulphate. The success of this repair was also evident from the gross appearance of the graft (Fig. 6).

Repair of control defects with metaplastic repair cartilage was seen in earlier grafts (Fig. 15) but after long periods there was a tendency for the repair tissue to break down (Fig. 16). Synovial pannus was noted in 13 grafted defects and of these only two (15\%) were successful, which appeared to indicate interference with graft incorportaion. Conversely, in 21 controls showing pannus, six $(28 \%)$ were successful which was not significantly different from the overall success rate of the controls.

\section{Results of grafting in arthritic joints}

Three groups of grafts were carried out in arthritic joints, namely intact articular cartilage, intact growth cartilage and cultured articular chondrocytes. In addition, the majority of the cultured grafts were cut to size with a metal bore in a manner similar to that used for the intact cartilage grafts. 
Table II. Success rate of repair in arthritic joints

\begin{tabular}{|c|c|c|c|c|c|c|c|c|c|}
\hline \multirow[b]{2}{*}{ Type of graft } & \multicolumn{5}{|c|}{ Age of graft at postmortem analysis } & \multicolumn{2}{|c|}{ Total successful } & \multicolumn{2}{|c|}{ Complete filling } \\
\hline & 2 weeks & 6 weeks & 3 months & 6 months & 1 year & No. & $\%$ & No. & $\%$ \\
\hline Cultured articular chondrocytes* & $1 / 3$ & $3 / 3$ & $1 / 4$ & $2 / 4$ & $1 / 4$ & $\begin{array}{l}* 5 \text { w cult } 0 / 6 \\
\text { *6w cult } 8 / 12 \\
P<0.05\end{array}$ & $\begin{array}{r}0 \\
67\end{array}$ & $\begin{array}{l}0 / 6 \\
5 / 12\end{array}$ & $\begin{array}{r}0 \\
42\end{array}$ \\
\hline Intact articular cartilage & $2 / 3$ & $4 / 4$ & $4 / 4$ & $3 / 3$ & $3 / 4$ & $\begin{array}{l}16 / 18 \\
P<0.01\end{array}$ & 89 & $15 / 18$ & 83 \\
\hline Intact growth-plate cartilage & $2 / 3$ & $4 / 4$ & $4 / 4$ & $3 / 4$ & $1 / 2$ & $\begin{array}{l}14 / 17 \\
P<0.01\end{array}$ & 82 & $10 / 17$ & 59 \\
\hline Controls & $0 / 9$ & $3 / 11$ & $7 / 10$ & $2 / 10$ & $1 / 10$ & $13 / 50$ & 25 & $5 / 50$ & 10 \\
\hline
\end{tabular}

* 5 -week cultures in 6 cases, 6 -week cultures in 12 cases

Table III. The effect of the stage of the arthritis on the rate of successful repair

\begin{tabular}{|c|c|c|c|c|c|c|c|c|}
\hline & \multicolumn{2}{|c|}{ No arthritis } & \multicolumn{2}{|c|}{ Minor arthritis } & \multicolumn{2}{|c|}{ Pronounced arthritis } & \multicolumn{2}{|c|}{ Total successful } \\
\hline & No. & $\%$ & $\overline{\text { No. }}$ & $\%$ & No. & $\%$ & No. & $\%$ \\
\hline Grafted & $5 / 7$ & 71 & $13 / 18$ & 72 & $20 / 28$ & 71 & $38 / 53$ & 72 \\
\hline Control defects & $2 / 6$ & 33 & $7 / 23$ & 30 & $4 / 21$ & 19 & $13 / 50$ & 26 \\
\hline
\end{tabular}

The results of these grafts are shown in Table II. Both intact articular and growth-plate grafts produced more frequent repair than that seen in ungrafted control defects $(P<0.01)$. As with the normal joints, there was evidence of a change in appearance of the growth-plate cartilage grafts after a prolonged period (Fig. 17). In the cultured chondrocyte group, although the overall repair was not significantly better than in control defects, the repair produced by chondrocytes cultured for six weeks as opposed to five weeks was significantly different from the controls $(P<0.05)$. The cultured articular chondrocytes could clearly be seen in early grafts, which contrasted with results in the normal joints where there was often no evidence of the graft, suggesting it had been lost from the defect. In one case of a long-term graft, incorporation was complete at the articular surface (Fig. 18) but the cartilage damage in this joint was slight. Control defects again demonstrated repair with metaplastic fibrocartilage although this tended to have a fibrous surface.

The arthritis produced by the papain did not produce consistent results in all instances: in seven joints which were grafted, and six control joints, no apparent change from normal was recorded; in 18 joints receiving grafts and 23 controls only early changes with loss of metachromatic staining were evident; and finally, in 28 grafted joints and 21 control joints more advanced changes were seen with fibrillation and the formation of cell clusters and cell cysts. The success of repair in these different groups is shown in Table III. It is interesting that $72 \%$ of grafts were successful when transplanted into arthritic joints, but in ungrafted defects of the control arthritic joints, repair occurred in only $26 \%$. These results suggest that cartilage allografts can survive in arthritic joints but the variability of the arthritis makes strict comparison difficult. In comparison to normal joints the formation of pannus did not appear to have a significant effect on the success of repair in grafted or control defects.

\section{DISCUSSION}

Normal joints. All types of graft produced repair more frequently than was seen in ungrafted control defects, although only in the intact articular and intact growthplate cartilage grafts was this significant $(P<0.01$ and $P<0.05$ respectively). There did not appear to be a problem with rejection of the grafts, but there was a significant effect produced by synovial pannus which has been suggested as a cause of graft failure (Yablon et al. 1977). It appeared that intact grafts only failed if they were badly positioned in the defect, as this may hinder their nutrition (McKibbin and Ráliš 1978). The intact articular cartilage graft after a prolonged period formed an articular surface almost indistinguishable from that of the recipient; although there was not always complete union of the graft at the surface, sulphate uptake was comparable. The long-term growth-plate grafts tended to show a modified appearance, with formation of an articular surface. It has been suggested by Benum (1974) that the cells in the proliferative zone have this ability to transform and failures may have been due to incompleteness of this zone. The consistent appearance of the grafts through increasing time periods almost certainly indicates that repair was by the graft, and in none of the long-term controls was the repair surface as good.

It has been suggested that failures in the isolated chondrocyte grafts were probably due to loss of the cells from the defect (Bentley and Greer 1971). It seemed probable that this loss was responsible for failure since in some of the two-week grafts there was no evidence of the graft at all. The cultured chondrocytes appeared to have 
maintained their phenotype after the six weeks in culture and high-density culture has been shown to influence this (Müller et al. 1977). The slightly poorer results produced by cultured growth of chondrocytes may have resulted from the method of culture. The proliferative zone cells have been shown to take up to 10 days to attach to the culture vessel surface (Corvol, Dumontier and Rappaport 1975), so that these may have been removed with the first changes in the culture medium. As it has been suggested that these cells are important for forming an articular surface, their absence from the culture or even the disorganised pattern taken up in the culture may have led to failure.

The repair seen in controls was always less than that seen in grafted defects and over the long term there was a tendency for the surface to break down. This supports previous observations that the metaplastic repair cartilage eventually reverts to fibrous tissue (Mitchell and Shepard 1976).

Arthritic joints. The arthritis produced was variable and in no case was there complete loss of the articular surface. These results may have been due to the potency of the crude papain during the final experiments being different from that originally used (Bentley 1971). A decrease in both allograft success and repair by metaplastic cartilage was seen with increasing signs of arthritic change, but this was less pronounced in the former. As in the normal joints, intact articular and growth-plate cartilage grafts produced a significantly better repair than was seen in the control defects $(P<0.01)$. The intact growth cartilage again demonstrated the ability to form an articular surface. The six-week cultures of cultured chondrocytes also produced better repair than the fiveweek cultures and were significantly better than the controls $(P<0.05)$. Their increased success was attributed to their being cut to a precise fit and so preventing loss from the defect. The five-week cultured chondrocyte allografts produced no repair, which may have been an indication of a deficiency in the matrix; the six-week cultures had a much firmer consistency. The control defects showed a similar repair pattern to that in the normal joints. This may have been due to the synovial reaction occurring prior to grafting, i.e. following the papain injections.

Conclusions. These results indicate that it is possible to repair limited defects in articular cartilage in mature rabbits by using intact articular cartilage allografts, providing the grafts are correctly positioned; this method should be applicable to man. In addition, it may be possible to use in vitro culture as a method of banking chondrocytes prior to grafting, although the much smaller amount of matrix produced by human chondrocytes may necessitate incorporation of these cultured cells into an artificial matrix such as carbon fibre or collagen sponge before grafting. The potential for treatment of early osteoarthritis, osteochondritis dissecans, osteochondral fractures and chondromalacia patellae by cartilage allografts is considerable.

\section{ACKNOWLEDGEMENTS}

We would like to thank Dr Helen Beard and Mrs Sally Roberts, from the Charles Salt Institute, Robert Jones \& Agnes Hunt Orthopaedic Hospital, Oswestry, for carrying out the indirect immunofluorescence assays on proteoglycan and collagen, and Mrs C. Oliver and Mrs E. Brandwood for preparation of histological sections. Our thanks are also due to Mrs L. P. Toms who prepared this manuscript.

We wish to acknowledge the generosity of the Arthritis and Rheumatism Council in supporting this work and for payment of the salary of J.E.A.

\section{REFERENCES}

Aston JE. Biological repair of articular surfaces: an experimental study. PhD Thesis, University of Liverpool, 1980.

Bentley G. Papain induced degenerative arthritis of the hip in rabbits. $J$ Bone Joint Surg [Br] $1971 ; 53$ B:324 37 .

Bentley G, Greer RB. Homotransplantation of isolated epiphyseal and articular cartilage chondrocytes into the joint surfaces of rabbits. Nature 1971;230:385-8.

Bentley G, Smith AU, Mukerjhee R. Isolated epiphyseal chondrocyte allografts into joint surfaces: an experimental study in rabbits. Ann Rheum Dis 1978;37:449-58.

Benum P. Autogenous transplantation of apophyseal cartilage to osteochondral defects of joints: an experimental study in dogs. Acta Orthop Scand 1974; Suppl 156

Chesterman PJ, Smith AU. Homotransplantation of articular cartilage and isolated chondrocytes: an experimental study in rabbits. $J$ Bone Joint Surg [Br] 1968;50-B: 184-97.

Cheung HS, Cottrell WH, Stephenson K, Nimni ME. In vitro collagen biosynthesis in healing and normal rabbit articular cartilage. $J$ Bone Joint Surg $[\mathrm{Am}]$ 1978;60-A:1076-81.

Coletti JM Jr, Akeson WH, Woo SL-Y. A comparison of the physical behaviour of normal articular cartilage and the arthroplasty surface. J Bone Joint Surg [Am] 1972;54-A:147-60.

Corvol MT, Dumontier MF, Rappaport R. Culture of chondrocytes from the proliferative zone of epiphyseal growth plate cartilage from prepubertal rabbits. Biomedicine $1975 ; 23: 103-7$.

Convery FR, Akeson WH, Keown GH. The repair of large osteochondral defects: an experimental study in horses. Clin Orthop 1972;82: 253-62.

Elves MW. The immunobiology of joints. In: Sokoloff L, ed. The joints and synovial fluid. New York, etc: Academic Press, 1978;i:332-93.

Eyre DR, Muir H. The distribution of different molecular species of collagen in fibrous, elastic and hyaline cartilages in the pig. Biochem $J$ 1975;151:595-602.

Fitton-Jackson $\mathbf{S}$. The influence of tissue interactions and extracellular macromolecules on the control of phenotypic expression and synthetic capacity of bone and cartilage. In: Slavkin HC, Greulich $\mathrm{RC}$, eds. Extracellular matrix influences on gene expression. New York, etc: Academic Press, 1975:489-95.

Furukawa T, Eyre DR, Koide S, Glimcher MJ. Biochemical studies on repair cartilage resurfacing of experimental defects in the rabbit knee joints. J Bone Joint Surg [Am] 1980;62-A:79-89.

Green WT. Articular cartilage repair: behaviour of rabbit chondrocytes during tissue culture and subsequent allografting. Clin Orthop 1977; 124:237-50.

Gross AE, Langer F, Houpt J, Pritzker K, Friedlaender G. Allotransplantation of partial joints in the treatment of osteoarthritis of the knee. Transplant Proc 1976;8 (2 Suppl 1): 129-32.

Langer F, Gross AE, West M, Urovitz EP. The immunogenicity of allograft knee joint transplants. Clin Orthop 1978;132: 155-62.

McKibbin B. Immature joint cartilage and the homograft reaction. $J$ Bone Joint Surg [Br] 1971;53-B: 123-35.

McKibbin B, Rális ZA. The site dependence of the articular cartilage transplant reaction. J Bone Joint Surg [Br] 1978;60-B:561-6.

Mankin HJ. Current concepts review: the response of articular cartilage to injury. J Bone Joint Surg [Am] 1982;64-A:460-6.

Miller EJ. Biochemical characteristics and biological significance of the genetically distinct collagens. Moll Cell Biochem 1976;13:165-92.

Müller PK, Lemmen C, Gay S, Gauss V, Kuhn K. Immunochemical and biochemical study of collagen synthesis by chondrocytes in culture. Exp Cell Res 1977;108:47-55.

Mitchell N, Shepard N. The resurfacing of adult rabbit articular cartilage by multiple perforations through the subchondral bone. $J$ Bone Joint Surg [Am] 1976;58-A:230-3.

Yablon IG, Brandt KD, Delellis R, Covall D. Destruction of joint homografts: an experimental study. Arthritis Rheum 1977;20:1526-37. 


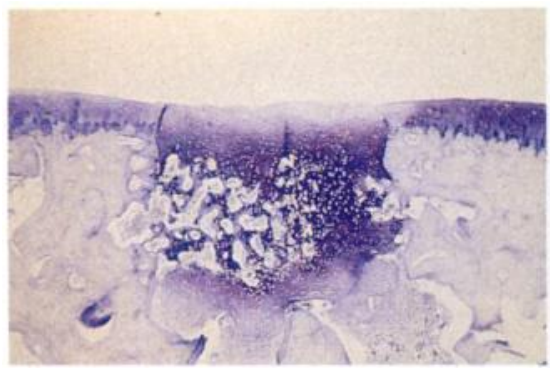

Fig. 7

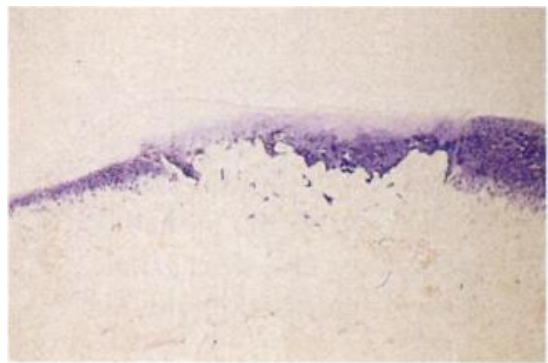

Fig. 9

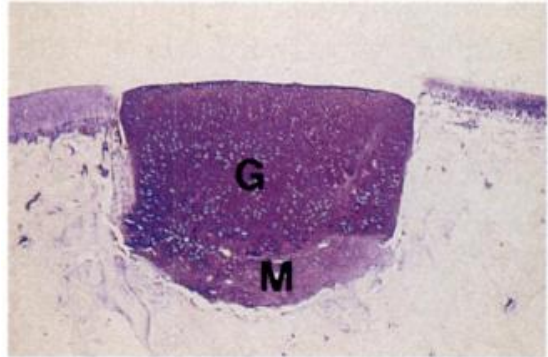

Fig. 10

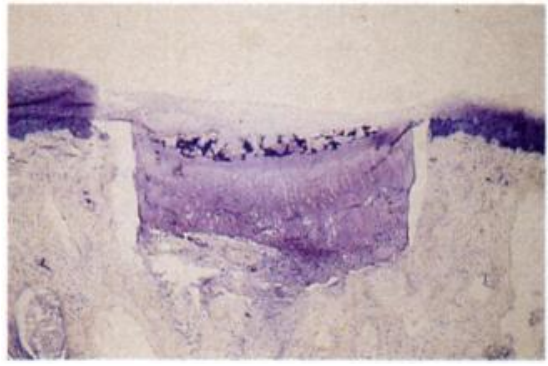

Fig. 13

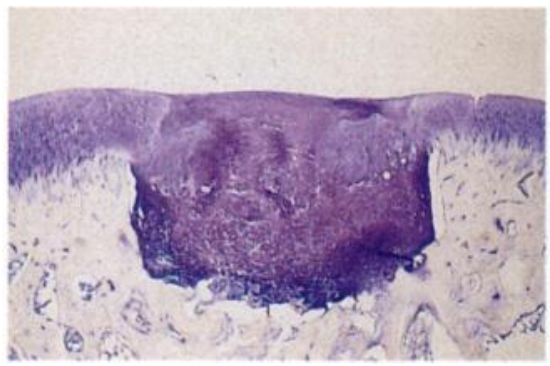

Fig. 15

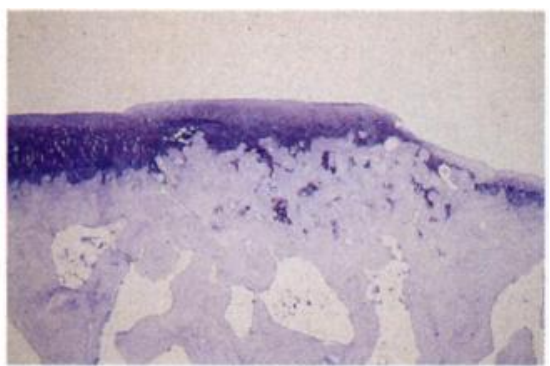

Fig. 17

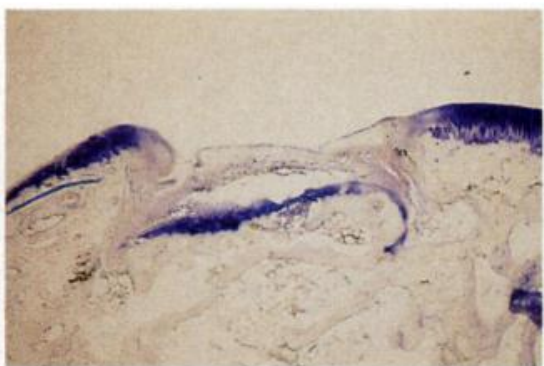

Figure 7-Successful. Six-week allograft of isolated growth-plate chondrocytes showing complete incorporation (toluidine blue, $\times 60$ ). Figure 8-Unsuccessful. Intact articular cartilage plug which had sunk below the surface and consequently failed to repair the defect (toluidine blue, $\times 90$ ).

Fig. 8

Figure 9-Six-month graft of cultured growth-plate chondrocytes showing partial replacement of the base with bone. The articular surface shows a slightly fibrous appearance (toluidine blue, $\times 90)$.

Intact articular cartilage graft. Figure 10-Six-week allograft of an intact articular cartilage plug showing metaplastic cartilage $(M)$ of the recipient merging with the donor cartilage $(G)$ of the graft (toluidine blue, $\times 90$ ). Figure 11 -Intact articular cartilage plug one year after grafting, with the surface showing an appearance similar to that of the recipient cartilage (toluidine blue, $\times 90$ ). Figure 12 -Autoradiograph of a six-month intact articular plug showing incorporation with the recipient cartilage and uptake of ${ }^{35}$ S]sulphate which appears comparable with the recipient cartilage $(\mathrm{H} \& \mathrm{E}, \times 90)$.

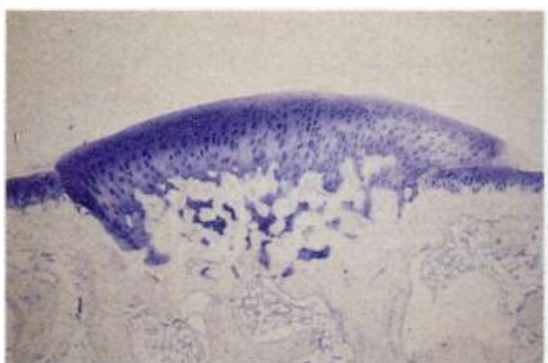

Fig. 11

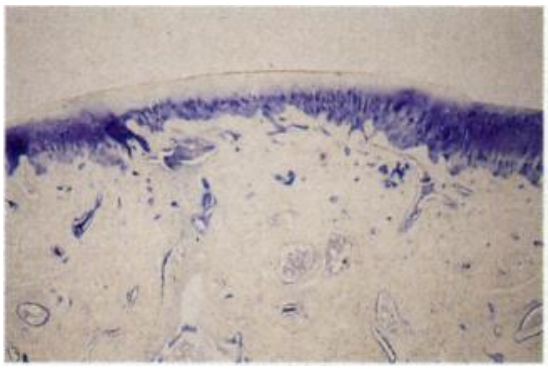

Fig. 14

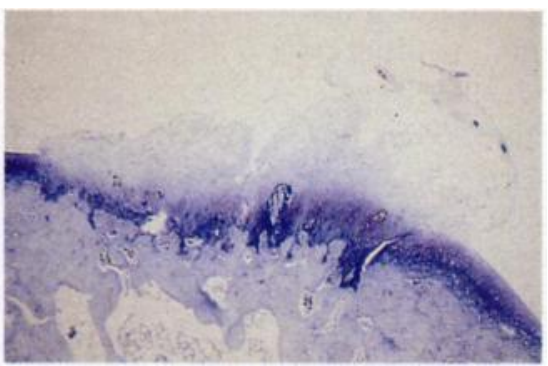

Fig. 16

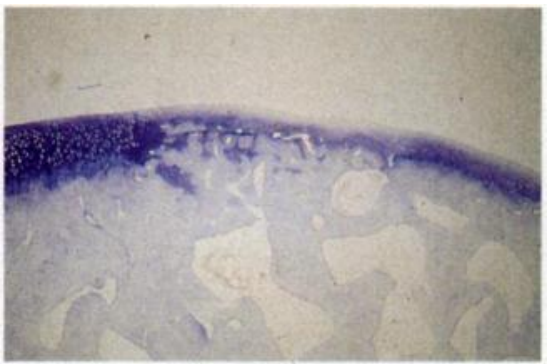

Fig. 18

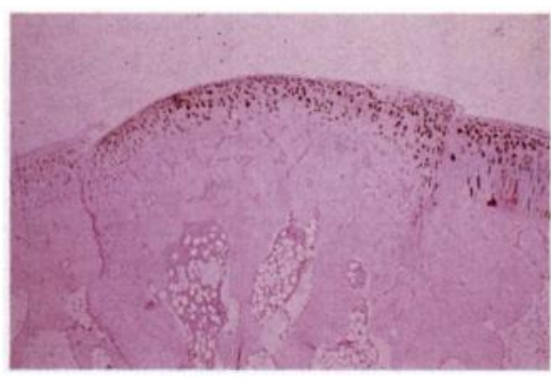

Fig. 12

Intact growth-plate cartilage grafts. Figure 13-Two-week allograft of an intact growthplate cartilage plug showing the typical morphology of the growth plate. The resting zone, proliferative zone and hypertrophic zone are clearly seen. Figure 14 One year allograft of an intact growth-plate cartilage plug showing complete incorporation, with the formation of an articular surface which is almost indistinguishable from that of the recipient cartilage.

Controls. Figure 15-Six-week control showing complete filling with metaplastic cartilage. The disorganised structure with relatively few cells distinguishes this from a grafted defect. Figure 16-Control defect after one year showing breakdown of the fibrocartilage surface tissue.

Grafts in arthritic joints. Figure 17-Intact growth-plate graft six months after grafting into an arthritic joint. Note the complete loss of articular cartilage alongside the graft. The graft remains healthy and apparently incorporated. Figure 18-Allograft of cultured articular chondrocytes after one year showing complete incorporation.

(Figs 13-18: toluidine blue, $\times 90$ ). 